\title{
Development of microforming process combined with thin film transfer printing
}

\author{
Kazushi Koshimizu*, Qiu Zheng, Tetsuhide Shimizu, and Ming Yang \\ Tokyo Metropolitan University, 6-6 Asahigaoka, Hino-shi, Tokyo 191-0065, Japan
}

Received 13 January 2015 / Accepted 28 February 2015

\begin{abstract}
Microforming receives a lot of attentions in the recent years due to the increased use of microparts in electronics and medical sectors. For the further functionalization of these micro devices, high functional surface with noble metals are strongly required for the devices in bio- and medical fields, such as bio-sensors. To realize the submillimeter structure of metal foils and micro to nanometer structures in one forming process, the present study proposes a combined process of microforming for metal foils and transfer printing of gold (Au) thin films. To clarify the availability of the proposed combined process, transferability of Au thin films under micro bulging deformation are investigated. $0.1 \mathrm{~mm}$-thick pure titanium (Ti) foils and $100 \mathrm{~nm}$-thick $\mathrm{Au}$ films were used as blank and functional materials, respectively. The forming tests of the proposed process were conducted. With increasing strain of Ti foils, $\mathrm{Au}$ TP areas increase. By this experiment, it's confirmed that the hydrogen reduction of oxidation layers and the strain of $\mathrm{Ti}$ foil are significant factor for $\mathrm{Au} \mathrm{TP}$ on Ti foils.
\end{abstract}

Key words: Microforming, Transfer printing, Ti foils, Au thin films, Micro bulging

\section{Introduction}

Because of low cost, high productivity and stability of process, the demand of micro press forming is increasing to realize small devices made by metallic parts taking advantage of good properties of metals, such as mechanical strengths, electrical conductivity and chemical resistance. Especially for medical devices, biocompatibility of metal has been highly required, and its miniaturization technology is needed. Additionally bio-devices with noble metal, such as gold $(\mathrm{Au})$ on the surface, are often used in bio-technology by exerting good functions like detecting antibody [1] or catalytic reaction [2]. Therefore, the process to fabricate the functional surface, which is combined with the biocompatible bulk metals is importance in the fabrication of bio- and medical devices.

In the present study, a process with the combination of micro press forming and fabrication of the functional surface for metal foils is proposed. This process can realize the submillimeter structure of metal foils and micro to nanometer structures of noble metals in one step. In this process, transfer printing (TP) [3] is selected to fabricate the functional surfaces. As shown in Figure 1, the noble metal films of $\mathrm{Au}$ is first deposited on the punch, and then micro press forming process is conducted to transfer $\mathrm{Au}$ to the processed material (Ti).

However, the availability of this combined process is not reported and the significant factors for this TP are not clarified yet. Thus, the aim of this study is to clarify the availability of

*e-mail: koshimizu-kazushi@ed.tmu.ac.jp the proposed process and to investigate the factors influencing the TP of $\mathrm{Au}$ thin films to Ti foils after press forming.

\section{Experiment}

\subsection{Au TP on Ti thin films}

To realize Au TP on Ti foils, basic parameter for Au TP on $\mathrm{Ti}$ have to be investigated. In recent studies, Hur et al. [4] reported that temperature, pressure and time have influence on the TP rate. Taniguchi et al. [5] reported that the atmosphere of TP and released layer under thin Au films also influenced the TP rate. According to these previous reports, the present study investigates the transferability of $\mathrm{Au} \mathrm{TP}$ on $\mathrm{Ti}$ substrate under these parameters.

Thin Ti film and Au film were deposited by electron cyclotron resonance sputtering machine (ELIONIX Corp.) on Silicon (Si) substrate, respectively. The thickness of $\mathrm{Ti}$ is $500 \mathrm{~nm}$, while the thickness of $\mathrm{Au}$ is $100 \mathrm{~nm}$. As shown in Figure 2, Thin Ti film was deposited on the Si substrate uniformly and $\mathrm{Au}$ films were patterned on the $\mathrm{Si}$ substrate with a width of $50 \mu \mathrm{m}$ and a pitch of $100 \mu \mathrm{m}$. But, in the case of any condition, the released layer of $\mathrm{Cr}_{2} \mathrm{O}_{3}$ was deposited under $\mathrm{Au}$ films.

After preparing two substrates, Ti film was first placed on the surface of $\mathrm{Au}$ film, and then was put in a chamber to be heated under the atmosphere of pure argon gas or mixed gas of hydrogen and argon with load for TP. TP conditions are 


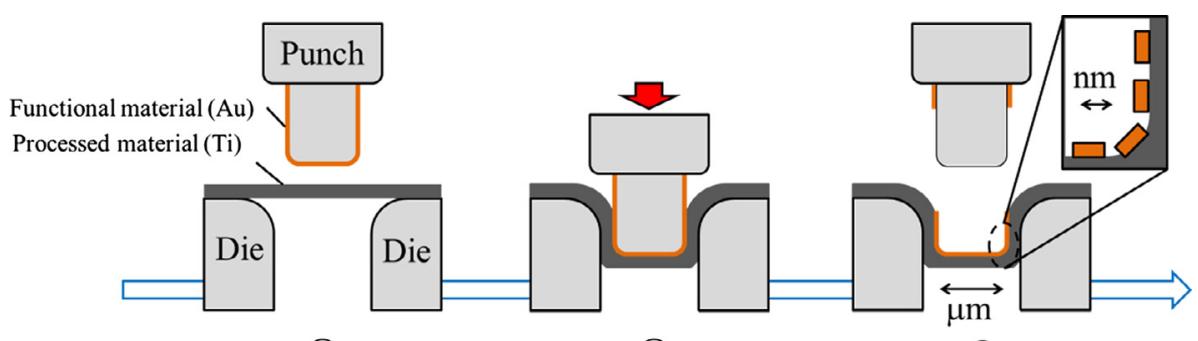

(1)

(2)

(3)

Figure 1. Schematic illustration of the proposed process with the combination of micro press forming and transfer printing.


(a)

(b)

Figure 2. (a) Schematic illustration of Si substrate deposited Ti and Au respectively, (b) SEM image of Au.

Table 1. Conditions of Au transfer printing (TP).

\begin{tabular}{lccccc}
\hline & Atmosphere & Temperature $\left({ }^{\circ} \mathrm{C}\right)$ & TP pressure $(\mathrm{kPa})$ & TP time $(\mathrm{min})$ & Release layer \\
\hline $\mathrm{A}$ & $\mathrm{Ar}$ & 700 & 150 & 30 & $\mathrm{SiO}_{2}$ \\
$\mathrm{~B}$ & $\mathrm{H}_{2} / \mathrm{Ar}$ & 700 & 150 & 30 & $\mathrm{SiO}_{2}$ \\
$\mathrm{C}$ & $\mathrm{H}_{2} / \mathrm{Ar}$ & 800 & 450 & 30 & $\mathrm{SiO}_{2}$ \\
$\mathrm{D}$ & $\mathrm{H}_{2} / \mathrm{Ar}$ & 800 & 450 & 30 & $\mathrm{Cr}_{2} \mathrm{O}_{3}$ \\
\hline
\end{tabular}

shown in Table 1. To evaluate the feasibility of functional surface made by this process, TP rate defined as the ratio of the area of printed $\mathrm{Au}$ to deposited $\mathrm{Au}$ in a square area of $1 \mathrm{~mm} \times 0.6 \mathrm{~mm}$ is calculated (see Figure 3).

\subsection{Au TP on the deformed Ti foil}

To investigate the influencing factors of $\mathrm{TP}$ of $\mathrm{Au}$ on deformed Ti foils, press forming system was developed (see Figure 4). This system mainly consists of a servo press machine, vacuum chamber, rotary pump, die for bulging process and resistance heating equipment. This system can realize the controlling of atmosphere and temperatures of Ti foil.

As shown in Figure 5, back plates of SUS deposited $\mathrm{Au}$ thin films were put under $0.1 \mathrm{~mm}$-thick Ti foils. The thickness of back plate is also $0.1 \mathrm{~mm}$. The patterns of thin Au films deposited on the back plate are the same as shown in Figure 2 and the released layer was $\mathrm{Cr}_{2} \mathrm{O}_{3}$ in this experiment. To reduce the oxidation layer of the Ti foils, the specimens were annealed at $700{ }^{\circ} \mathrm{C}$ with the atmosphere of $\mathrm{H}_{2}$ for $30 \mathrm{~min}$ before bulging. After bulging, the keeping time of punch for TP was $30 \mathrm{~min}$. Then the Au films can be transferred to the deformed Ti foils. Other experimental conditions, such as the atmosphere for bulging, strain of deformed area and TP pressures, are shown in Table 2. To investigate the strain of the deformed area of Ti foil and back plate, the bulging process was analyzed by finite element method (FEM) using ABAQUS. The schematic illustration of the model is shown in Figure 6. As shown in Table 3, where, the mesh size of specimens was $25 \mu \mathrm{m} \times 25 \mu \mathrm{m}$, the punch stroke was 1 or $2 \mathrm{~mm}$ from the punch contacted with Ti foil, the mass density of Ti foil and back plate were $4.5 \times 10^{-9}$ and $7.9 \times 10^{-9}\left(\mathrm{mg} / \mu \mathrm{m}^{3}\right)$, the young's modulus of them were 110 and $171(\mathrm{GPa})$, the yield stress of them were 330 and $292(\mathrm{MPa})$, the poisson's ratio of them were 0.34 and 0.28 , and the friction coefficient was 0.1 . 


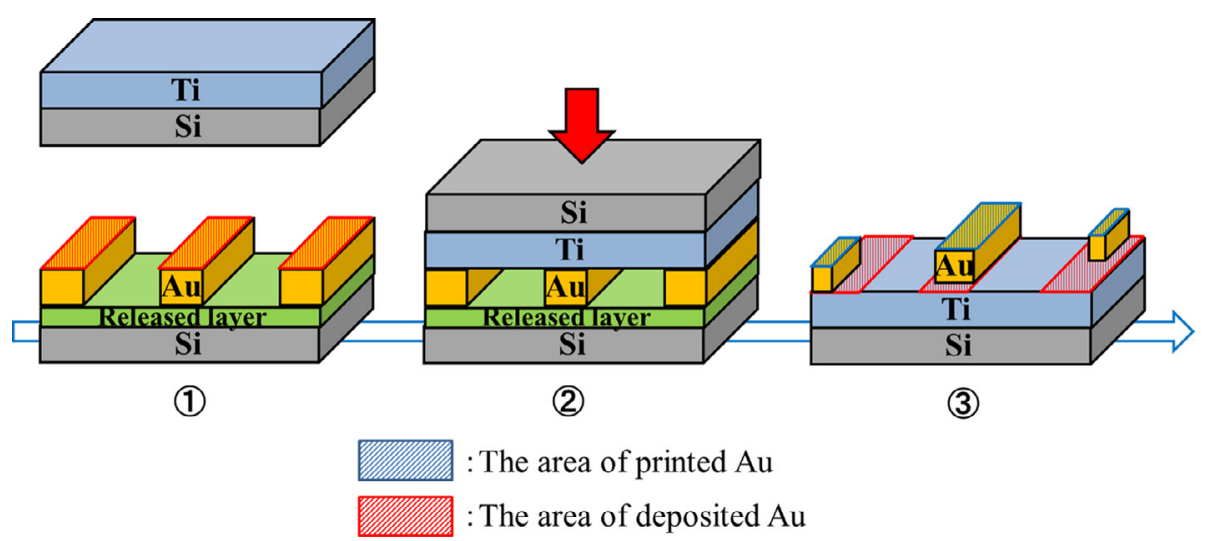

Figure 3. Schematic illustration of transfer printing.

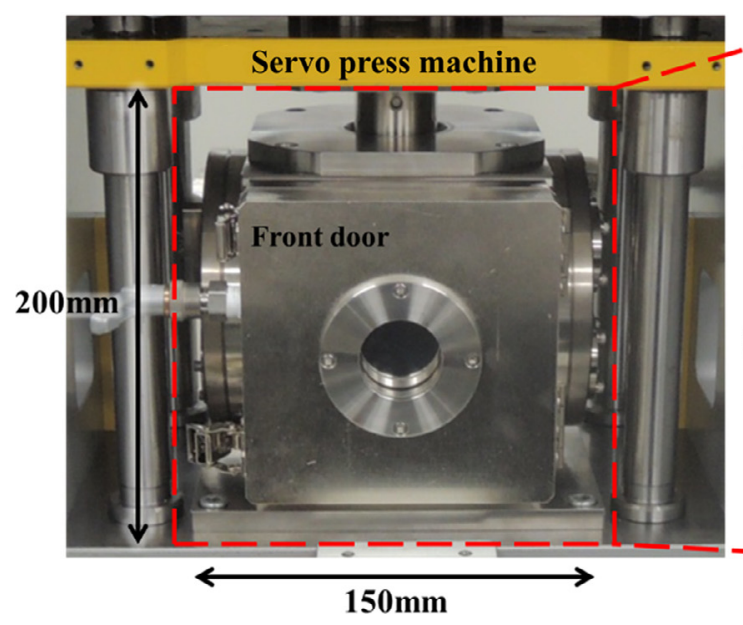

(a)

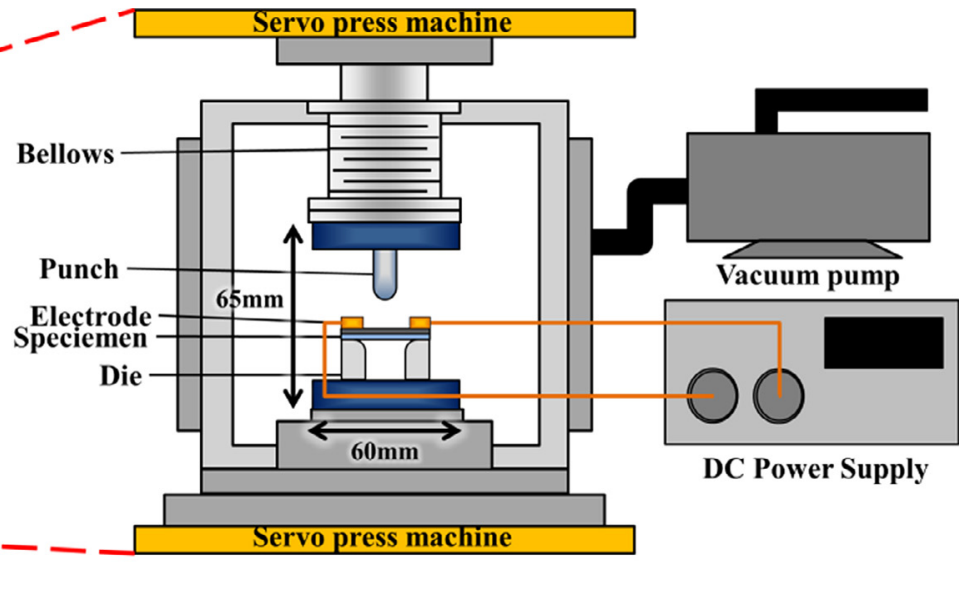

(b)

Figure 4. Developed press forming system (a) appearance of chamber, (b) schematic illustration.

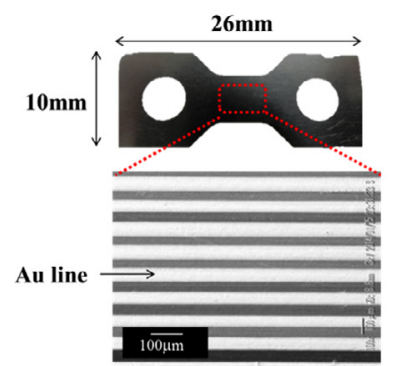

(a)

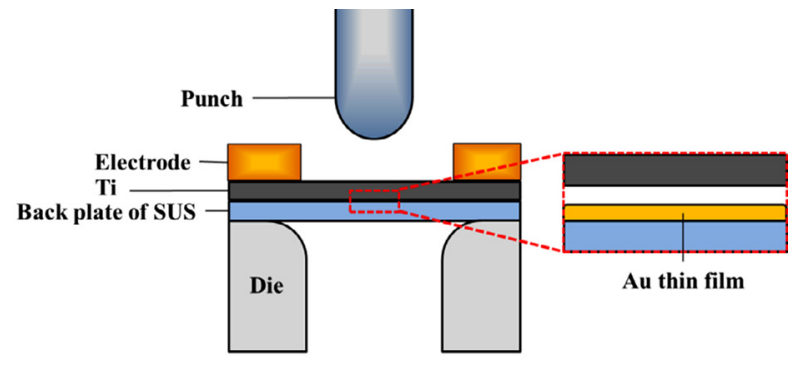

(b)

Figure 5. (a) Shape of back plate and SEM image of surface, (b) schematic illustration of die for bulging process.

\section{Results and discussion}

\subsection{Au TP on Ti thin films}

Figure 7 shows the images of surfaces for Ti thin film after $\mathrm{Au}$ TP taken by scanning electron microscope (SEM) in the conditions of A-D. The qualitative analysis for these surfaces was taken by energy dispersive X-ray analyser (EDX). In condition A, no Au thin films were printed on Ti foils. However $\mathrm{Au}$ films can be found to be printed on Ti for the conditions B-D. The TP rate for conditions B-D is shown in Figure 8 . As the conditions change from $\mathrm{B}$ to $\mathrm{C}$ and $\mathrm{D}$, the $\mathrm{TP}$ rate 
Table 2. Conditions of Au TP on deformed Ti foil.

\begin{tabular}{lccc}
\hline & Atmosphere & Strain $(\%)$ & TP pressure $(\mathrm{N})$ \\
\hline $\mathrm{E}$ & $\mathrm{Ar}$ & 8.4 & 390 \\
$\mathrm{~F}$ & $\mathrm{H}_{2} / \mathrm{Ar}$ & 8.4 & 250 \\
$\mathrm{G}$ & $\mathrm{H}_{2} / \mathrm{Ar}$ & 2.6 & 390 \\
$\mathrm{H}$ & $\mathrm{H}_{2} / \mathrm{Ar}$ & 8.4 & 390 \\
\hline
\end{tabular}

Table 3. Input mechanical properties of specimens and FE simulation conditions.

\begin{tabular}{lcc}
\hline Specimen & $\mathrm{Ti}$ & Back plate (SUS) \\
\hline Mass density $(\mathrm{mg} / \mu \mathrm{m})$ & $4.5 \times 10^{-9}$ & $7.9 \times 10^{-9}$ \\
Young's modulus $(\mathrm{GPa})$ & 110 & 171 \\
Yield stress $(\mathrm{MPa})$ & 330 & 292 \\
Poisson's ratio & 0.34 & 0.28 \\
Friction coefficient & & 0.1 \\
\hline
\end{tabular}

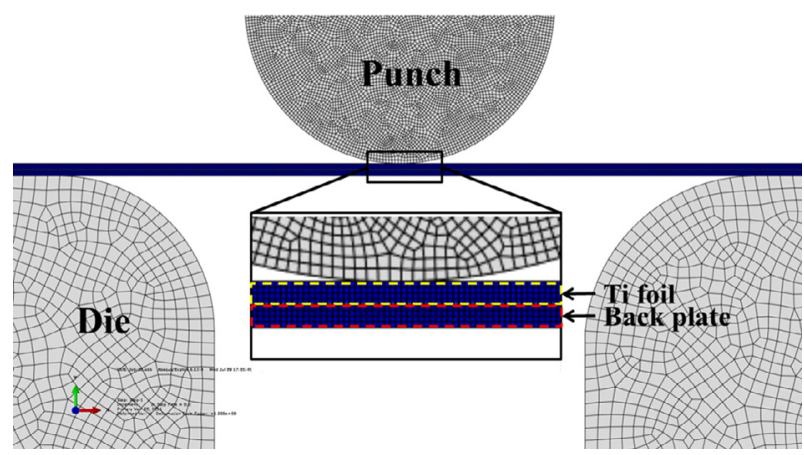

Figure 6. Schematic illustration of FEM model.
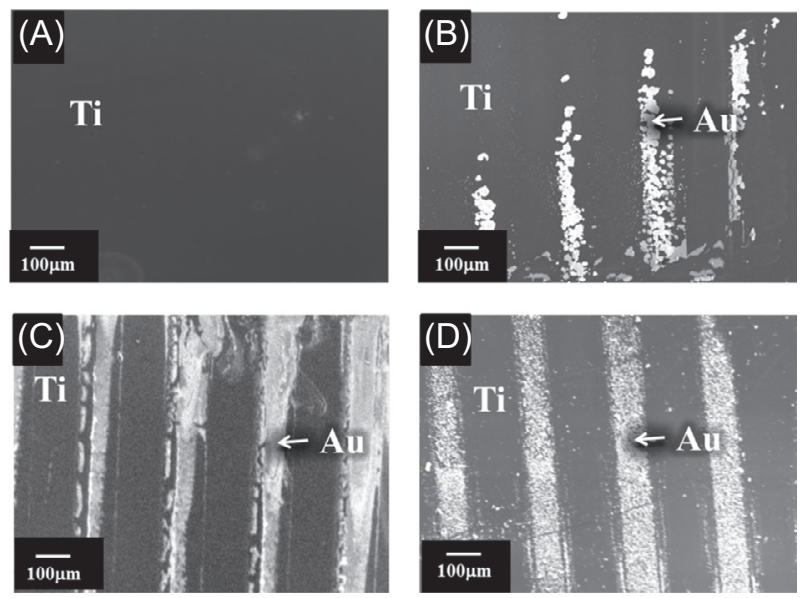

Figure 7. SEM image of $\mathrm{Au}$ thin films transfer printed on Ti thin films.

increases from $12 \%$ to $40 \%$ and to $43 \%$. From this measurement, it was confirmed that the atmosphere of $\mathrm{H}_{2}$ gas, high temperature of Ti film, high pressure of TP and release layer of $\mathrm{Cr}_{2} \mathrm{O}_{3}$ can increase $\mathrm{Au}$ TP rate. The effect of $\mathrm{H}_{2}$ gas can be explained by the reduction of oxidation layer of Ti due to

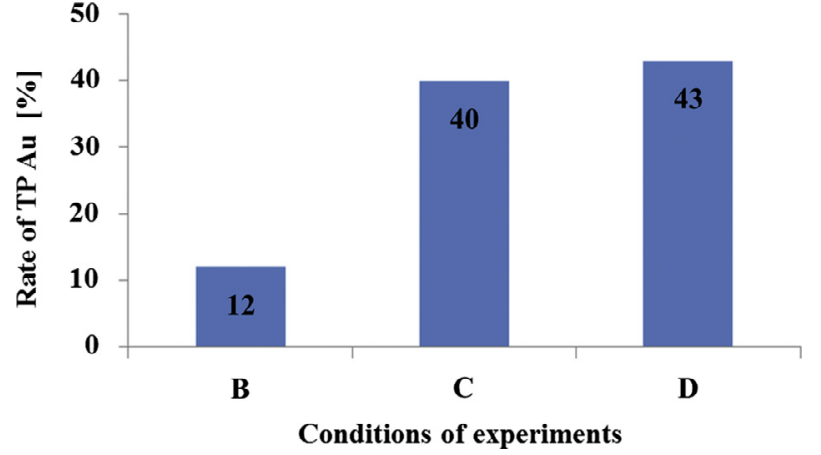

Figure 8. Rate of transfer printed Au thin films for three different conditions shown in Table 1.

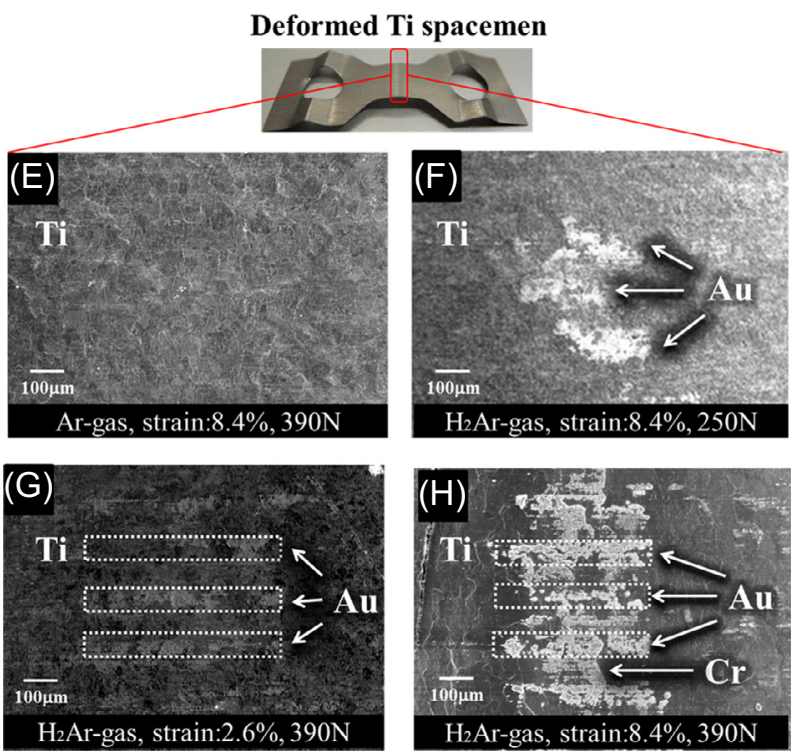

Figure 9. SEM image of Au thin films transfer printed on deformed Ti foils.

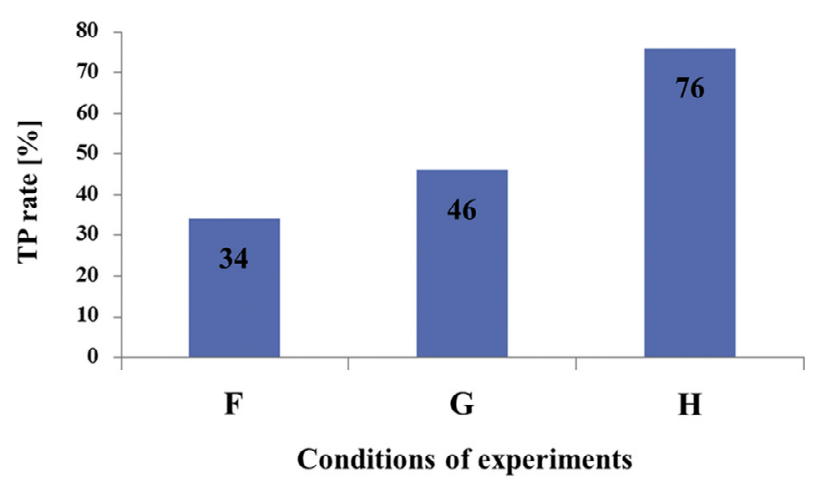

Figure 10. Rate of transfer printed $\mathrm{Au}$ thin films on deformed $\mathrm{Ti}$ foil $\mathrm{s}$ for three different conditions shown in Table 2.

the reaction with $\mathrm{H}_{2}$ gas under high temperature. Thus, Ti surface becomes active and the chemical reaction between $\mathrm{Ti}$ and $\mathrm{Au}$ is promoted. As TP temperature increases, this reaction is also promoted. The effect of TP pressure can be explained by 



Figure 11. Distribution of strain (a) punch stroke was $1 \mathrm{~mm}$ and strain of middle of Ti foil was $2.6 \%$, (b) punch stroke was $2 \mathrm{~mm}$ and strain of middle of Ti foil was $8.4 \%$.



Figure 12. Crack spacing of oxidation layer for different strain of Ti foil.

increasing the true contact area between $\mathrm{Ti}$ and $\mathrm{Au}$, which result in the increase of TP rate. The effect of release layer of $\mathrm{Cr}_{2} \mathrm{O}_{3}$ can be explained by the decrease in the binding energy of substrate with Au. Taniguchi et al. [5] reported that the adhesive force between two surfaces relates to these surface energy. This energy of $\mathrm{Cr}_{2} \mathrm{O}_{3}$ is smaller than $\mathrm{SiO}_{2}$. Therefore, $\mathrm{Au}$ thin films are easily released and transferred to Ti films.

\subsection{Au TP on the deformed Ti foil}

Figure 9 shows the images of surfaces for Ti foil after $\mathrm{Au}$ TP taken by SEM and EDX in the conditions of E-H. From these results, Au thin films were printed in deformed area of Ti foils. Figure 10 shows the Au TP rate on Ti foils. Here, $\mathrm{TP}$ rate is defined as the ratio of the area for printed Au to deposited $\mathrm{Au}$ in the square area of $500 \mu \mathrm{m} \times 50 \mathrm{~nm}$. It was confirmed that $\mathrm{Au}$ thin films were printed in $\mathrm{H}_{2} / \mathrm{Ar}$ gas. This indicates that the effect of the $\mathrm{H}_{2}$ reduction of oxidation layer has significant influence on TP. In addition, with increasing strain and TP pressure, Au TP rate increases. It was considered that high TP pressure enlarges true contact area between Ti and $\mathrm{Au}$, therefore $\mathrm{Au} \mathrm{TP}$ rate increases from condition $\mathrm{F}$ to $\mathrm{H}$. However, in condition $\mathrm{H}$, some $\mathrm{Cr}$ thin films were also printed on Ti surface. This effect of $\mathrm{Cr}$ TP can be explained by elastic deformation of $\mathrm{Au}$ thin films, which result in the contacting two surfaces of $\mathrm{Cr}$ and activated $\mathrm{Ti}$ in the condition of high TP pressure. With the further increase of strain, active surfaces of Ti foil seem to be exposed by the cracks of oxidation layer. As shown in Figure 11, the strain of Ti foil was concentrated around the radius of punch. Latella et al. [6] reported that the crack space of oxidation layer can be observed in the area with distribution of strain. These crack spacing were considered to expose the active surface of specimen. The crack spacing of oxidation layer is calculated by equation (1) [6]:

$$
C \mathrm{~s}=\frac{\sigma_{\mathrm{c}} t}{\tau}
$$

where, $C \mathrm{~s}$ is the crack spacing, $\sigma_{\mathrm{c}}$ is the fracture strength, $t$ is the thickness of oxidation layer, and $\tau$ is the interfacial shear strength. As shown in Figure 12, the crack spacing became from $160 \mathrm{~nm}$ to $421 \mathrm{~nm}$ as strain increased from $2.6 \%$ to $8.4 \%$. Therefore, the amount of exposed surface has the same effect as the reduction of the oxide surface under $\mathrm{H}_{2}$ atmosphere.

\section{Conclusions}

In this study, we proposed a process with the combination of micro bulging and transfer printing. The factors influence for the Au TP on Ti film and deformed Ti foil were investigated. The results of Au TP on Ti thin film showed that the atmosphere of $\mathrm{H}_{2}$, increasing TP temperatures, increasing TP pressure and release layer of $\mathrm{Cr}_{2} \mathrm{O}_{3}$ could increase the $\mathrm{Au}$ TP rate. In addition, the results of Au TP on deformed Ti foil showed that the strain of Ti foil influenced the Au TP rate significantly. It was considered that active surfaces exposed by the cracks of oxidation layer increased the reaction area for TP of $\mathrm{Au}$ on Ti foil.

In the future, the detail of relation between strain of Ti foil and $\mathrm{Au}$ TP rate and the influence of process parameters for the quality of Au films such as TP rate or feature will be considered in order to define, in detail, the process scope of this combining process.

\section{References}

1. X. Cao, Y. Ye, S. Liu, Gold nanoparticle-based signal amplification for biosensing, Anal. Biochem. 417 (2011) 1-16.

2. H. Zhao, Y. Wang, Q.H. Tang, et al., Pt catalyst supported on titanium suboxide for formic acid electrooxidation reaction, Int. J. Hydrogen Energy 39 (2014) 9621-9627.

3. J.W. Kim, K.Y. Yang, S.H. Hong, H. Lee, Formation of Au nanopatterns on various substrates using simplified nano-transfer printing method, Appl. Surf. Sci. 254 (2008) 5607-5611. 
4. S.H. Hur, D.Y. Khang, C. Kocabas, J.A. Rogers, Nanotransfer printing by use of noncovalent surface forces: applications to thin-film transistors that use single-walled carbon nanotube networks and semiconducting polymers, Appl. Phys. Lett. 85 (2004) 5730-5732.

5. J. Taniguchi, S. Ide, N. Unno, H. Sakaguchi, Nanoprint lithography of gold nanopatterns on polyethylene terephthalate, Microelectron. Eng. 86 (2009) 590-595.
6. B.A. Latella, B.K. Gan, H. Li, Fracture toughness and adhesion of thermally grown titanium oxide on medical grade pure titanium, Surf. Coat. Technol. 201 (2007) 6325-6331.

Cite this article as: Koshimizu K, Zheng Q, Shimizu T \& Yang M: Development of microforming process combined with thin film transfer printing. Manufacturing Rev. 2015, 2, 6 . 